Article

\title{
Absent Agroecology Aid: On UK Agricultural Development Assistance Since 2010
}

\author{
Michel P. Pimbert ${ }^{1, *(1)}$ and Nina Isabella Moeller ${ }^{2}$ \\ 1 The Centre for Agroecology, Water and Resilience, Coventry University, Ryton Gardens, Wolston Lane, \\ Coventry CV8 3LG, UK \\ 2 Marie Curie Research Fellow, School of Environment, Education and Development, University of \\ Manchester, Oxford Road, Manchester M13 9PL, UK; nina.moeller@manchester.ac.uk \\ * Correspondence: michel.pimbert@coventry.ac.uk; Tel.: +44-0-755-742-5256
}

Received: 29 December 2017; Accepted: 9 February 2018; Published: 13 February 2018

\begin{abstract}
Using figures published by the UK Department of International Development (DFID), this study finds that despite overwhelming evidence in favour of agroecology as a mode of agricultural development able to address crucial aspects of the interrelated crises facing human societies, UK development aid barely supports agroecology. Based on the most generous interpretation, this study shows for the first time that aid for agroecological projects is less than $5 \%$ of agricultural aid and less than $0.5 \%$ of total UK aid budget since 2010. Since 1 January 2010, no funds at all have been directed at or been committed to projects with the main focus on development or promotion of agroecological practices. Minor funds have been directed at projects which include some activities promoting agroecology at the most basic level of resource efficiency (e.g., conservation agriculture). By largely supporting industrial and Green Revolution agriculture, UK Aid priorities contribute very little to the transition towards social-ecological sustainability in Africa, Asia, and Latin America.
\end{abstract}

Keywords: development aid priorities; agroecology; food and agricultural policy; Green Revolution agriculture; sustainable development goals (SDGs)

\section{Introduction: Agroecology as Increasingly Recognized Pathway to a Sustainable Food System}

The International Assessment of Agricultural Knowledge, Science and Technology for Development (IAASTD) warned in its final report in 2008 that the global agriculture system will have to be radically transformed if the world is to avoid further environmental and social problems. "Business as usual is no longer an option" concluded the study commissioned by the UN and the World Bank after a three-year effort involving more than 400 scientists and 30 governments [1] (p. 3). Ratified by the UK alongside 57 other countries in April 2008 in Johannesburg, the report recommended a fundamental and deep rethinking of agricultural knowledge, science, and technology, with a view to achieving a sustainable global food system.

Although agricultural development and hence productivity has been uneven, globally more food per capita is produced than ever before and, arguably, more than is needed [2,3]. And while global agricultural productivity has vastly increased in the decades since the Second World War, the beginning of the 21st century was characterized by the realisation that despite these significant scientific and technological achievements, very little attention had hitherto been paid to their social and environmental consequences. According to recent estimates, approximately 795 million people are currently affected by hunger and undernourished [4], while 2 billion people are overweight and 650 million obese [5] (doubled since 1980); thus, the prevalence of overweight/obesity now represents a bigger cause of mortality than starvation [6]. This scenario is accompanied by a wide 
range of metabolic syndromes increasingly linked to cancer [7] and auto-immune conditions that are reaching epidemic proportions world-wide [8-11], as well as antibiotic resistance [12]. The future existence of clean water, fertile soils, healthy ecosystems, and biodiversity depend crucially on the way food is produced and hence on human diets [1,6]. In the context of a "world of asymmetric development, unsustainable natural resource use, and continued rural and urban poverty" [1] the IAASTD's landmark report recommended "enhanc[ing] sustainability while maintaining productivity in ways that protect the natural resource base and ecological provisioning of agricultural systems. Options include ... supporting agroecological systems" [1] (pp. 5-6).

Similarly, in the 2010 Report submitted to the Human Rights Council, Olivier De Schutter, the Special Rapporteur on the right to food, identifies agroecology as the mode of agricultural development which can "raise [agricultural] production where it needs most to be raised (i.e., in poor, food-deficit countries), while at the same time improving the livelihoods of smallholder farmers and preserving ecosystems" [13] (p. 3). Indeed, the report summarises research which shows that agroecology raises productivity at field level, decreases rural poverty, supports food security by improving nutrition, and plays a significant role in the adaptation to climate change. In doing so, agroecology also contributes significantly to meeting the SDGs-the Sustainable Development Goals [14], especially Sustainable Development Goal 2 to end hunger, achieve food security and improved nutrition, and promote sustainable agriculture (see also [15]). De Schutter's report argues that the scaling up of agroecology is the leading contemporary challenge.

The need to invest in agroecological research and innovations for sustainable development was highlighted by the European Union's Standing Committee on Agricultural Research (SCAR) in its third Foresight Report [16]. The EU's SCAR calls for research to create 'radically new farming systems' that must 'differ in significant respects from current mainstream production systems' [16]. High priority should be given to approaches and innovations that 'integrate historical knowledge and agroecological principles'.

It is noteworthy that the direct and indirect contributions of agroecology to the attainment of the UN Sustainable Development Goals are becoming increasingly apparent. For example, a meta-analysis of 50 case studies from 22 African countries [17] as well as evidence from Europe and Central Asia [18] suggest that agroecology contributes to at least 10 of the 17 SDGs-including no poverty (SDG 1), zero hunger (SDG 2), gender equality (SDG5), decent work and economic growth (SDG 8), responsible consumption and production (SDG 12), climate action (SDG 13), and life on land (SDG 15).

Agroecology is a science, a policy framework, a development methodology, a set of agricultural practices, and a social movement (cf. [19]). As a science, agroecology is the application of ecological science to the study, design and management of sustainable agroecosystems [20]. As a policy framework and a development methodology, it facilitates applying the scientific findings to projects "on the ground". As a set of agricultural practices, agroecology enhances farming systems by imitating and replicating natural processes, with a view to creating beneficial biological interactions, complementarities, and synergies among the different constituent parts of the agroecosystem. As a social movement, agroecology promotes viable alternatives to the dominant agro-food regime.

In this short paper, we take stock of the support provided to agroecology, both according to science and as a social movement, but above all as a set of practices, in terms of funding initiatives for agroecological improvements of food production systems through an analysis of development aid expenditure.

In order to account for the different ways in which development projects and agricultural practices can contribute to the development of agroecological food and farming systems, we adopt the framework established by Gliessman [21], which classifies practices based on their potential to make the system more sustainable according to five "levels," ranging from incremental to transformative (see also [22]):

Level 1: practices focus on increasing efficiency (resulting in, for example, reduced use of off-farm inputs such as fertilisers, pesticides, water, and energy; reduced waste; improved yields). 
Level 2: efforts substitute less damaging inputs and practices (e.g., replacing synthetic fertilisers with compost; using alternative pest-control; reduced soil tillage; organic farming systems).

Level 3: efforts integrate ecological practices and emphasize the redesign of systems based on ecological principles (to provide environmental and public health benefits while meeting food needs; e.g., complex crop rotations; agroforestry and polycultures; improving grazing systems through regenerative practices; crop and animal diversification to improve soil health and reduce pests).

Level 4: systems reinforce connections between producers and consumers (through enabling socio-economic measures such as policies and incentives to encourage the engagement of communities and businesses in sustainable operations; e.g., short food chains and webs, Community Supported Agriculture (CSA) schemes; re-localisation of food systems and markets within same territories).

Level 5: the agroecological practices of Level 3 and the alternative forms of economic exchange and market relationships of Level 4 are fully developed and integrated into a (global) sustainable food system.

We here present our recent analysis of UK development aid expenditure, asking how much money has been spent and committed since 1 January 2010 on projects that promote agroecology abroad, at any one of these five levels. The analysis in this paper is based on research completed in March 2017-we reran our database queries on 4 December 2017, and have included comments on the implications of the marginally changed results in the following sections.

\section{Methodology and the Limitations of Analysing Aid Flow Data}

Originally conceived as an analysis of wider European development aid flows, this study is focussed on UK foreign aid. This is due to the lack of availability of complete data on such flows from most European countries. By contrast, due to the 2010 UK Aid Transparency Guarantee, UK data is fully available for the period from 2010. The Guarantee is meant to ensure that the government publishes how UK aid money is spent, and who benefits from it, in a comparative format and an accurate and timely manner (even though this transparency is now said to be threatened by the Conflict, Stability and Security Fund (CSSF), launched in April 2015, which combines Official Development Assistance (ODA) with non-aid funding for programmes about which public information is not available [23]).

The UK government publishes information on money donated overseas in accordance with the International Aid Transparency Initiative (IATI). IATI, launched in Accra at the third High Level Forum on Aid Effectiveness in 2008, supports donors to meet their political commitments on transparency, as set out in the Accra Agenda for Action.

The IATI Standard is a technical publishing framework using XML (eXtensible Markup Language, designed to store and transport data), which allows the comparison of data from different sources. Any organisation engaged in development (such as government donors, private sector organisations, and Non Governmental Organisations-NGOs) can use the IATI Standard to publish data on development cooperation activities (such as transaction histories, geographic coding, classifications of funds-e.g., agriculture sector). Once published, the data gets linked to the IATI Registry and, if compliant, pulled into the IATI Datastore [24]. In this way, all data published to the IATI Standard can get queried in that single source. The Datastore also delivers selections of IATI data in JSON (JavaScript Object Notation, a lightweight data-interchange format) or CSV (spreadsheet) formats.

Without an appropriate software application, however, data from the Datastore remains difficult to use and analyse. The Development Portal (d-portal.org) is a tool that makes IATI data usable by providing information by country or by publisher on development activities and budgets published to the IATI platform and by providing a key word search function.

Unfortunately, d-portal is so far only available in a beta version, and an unsolved technical problem (identified during our queries) has made its use unreliable for our purposes and timeframe. We have hence used the UK Department for International Development (DFID)'s own application, Development Tracker, to explore aid flows from the UK Government. 
DFID's aid programme accounts for the majority of the UK's Gross Public Expenditure on Development (GPEX) or Official Development Assistance (ODA)—on average between 84\% and 85\% depending on figures used. The DFID programme as well as available GPEX figures report gross flows from the UK according to UK financial years rather than calendar years. Net Official Development Assistance (ODA), another important aid classification, is produced on a calendar year basis. ODA is compiled and reported according to an internationally agreed definition set by the Development Assistance Committee of the Organisation for Economic Cooperation and Development (OECD), and is therefore comparable with figures for other donors. ODA figures include money spent on annual subscriptions and contributions to international organisations (e.g., World Health Organisation, International Organisation of Migration), money spent on supporting refugees in the donor country, on supporting military and security forces in fragile states, and on certain diplomatic activities. DFID has started publishing their data as ODA figures from 2012. DFID's aid programme 2005/06 accounts for $88 \%$ of GPEX (excluding debt relief); $2006 / 0787 \%$ of GPEX (excluding debt relief); $2007 / 08$ 86\% of GPEX; 2008/09 81\% of GPEX; 2009/10 85\% of GPEX; 2010/11 85\% of GPEX; 2011/12 87\% of GPEX; $201287 \%$ of ODA; $201387.8 \%$ of ODA; $201486 \%$ of ODA; $201580.5 \%$ of ODA (due to increase in non-DFID departmental ODA). We have hence focused our analysis of UK aid flows on DFID spending. While DFID is by far the largest contributor of UK ODA, other departments with ODA budgets include the Foreign and Commonwealth Office (FCO), the Department for Environment, Food \& Rural Affairs (DEFRA), the Home Office, and the Department for Business, Energy and Industrial Strategy (BEIS, a merger of the former Department for Energy and Climate Change and the Department for Business, Innovation \& Skills). However, IATI data on the ODA commitments of FCO and BEIS is incomplete (activities listed, but without budgets). IATI data on the ODA commitments of DEFRA is available, but none of the 52 declared activities has been assigned an IATI-specific identifier, making it difficult to find detailed information on each. We identified five projects that could potentially have a supportive effect on agroecology with a total of $£ 267,791.15$ (11\% of total DEFRA ODA commitments), but have not included these in our calculations, both because of the relatively small numbers involved, and in order to concentrate this analysis on DFID spending for conceptual coherence.

We used Development Tracker to identify 181 projects in the agricultural sector with a start date from 1 January 2010, at any state of implementation (implementation, completion, or post-completion) (In December 2017, the number of projects identified with Development Tracker had risen to 187-one of the original 181 projects had disappeared from the new list of results and seven new projects were now included. Four of these new projects are not agricultural projects and must have been mislabelled and hence mistakenly appeared as results of our queries-a situation which raises additional questions of reliability of the overall data retrieved from Development Tracker. The remaining three projects are not promoting agroecology. The project that has disappeared from the list of results since March 2017 is also a project that is not promoting agroecology. We hold that these marginal changes in results do not affect the analysis presented in this paper). For each of these projects, we reviewed the information available publicly (IATI title, IATI description, and linked documents such as business cases and annual reviews) and categorised them as either "not promoting agroecology", "promoting agroecology", "partially promoting agroecology", or "potentially promoting agroecology". The latter category includes projects that might indirectly promote agroecology—e.g., through policy development and research support—but for which specific evaluations would be necessary in order to determine the actual impact. This category also comprises projects about which not enough information is available but whose title suggests the possibility of activities supporting agroecological practices.

Given that "promotes agroecology" is not a tick box in a standardised IATI format where the 'tickedness' can be straightforwardly determined, our analysis is partly of a qualitative nature. Moreover, not all project entries contain the same type of information, such as linked documents, which has complicated comparability. Not least because of these limitations, we have chosen to err on the generous side and have interpreted "support for" or "promotion of" agroecology in the widest possible senses. 
It also bears mentioning that we have completely sidestepped the question of which part of a project budget actually ends up contributing to the project aims and objectives "on the ground". We are under no illusion that the entirety of a project's budget will support activities that contribute to the project aims, or be efficiently spent. Nonetheless, we are using the budget figures as if their relationships to the project aims were unproblematic.

\section{Discussion of Results: On the Near-Absence of Aid to Agroecology}

Of the 181 projects reviewed, with a combined budget of almost $£ 6$ billion $(£ 5,845,427,149)$ (taking into account the changes of December 2017 mentioned above, the budget would increase to $£ 5,863,930,686$ counting the three additional agricultural projects, and to $£ 6,347,730,685$ counting all additional projects), none was found to be aimed at promoting agroecology, at none of the five levels. Seven projects, however, were found to be partially contributing to agroecology. This means that they include activities aimed at generating agroecological improvements, even though some of their activities will be irrelevant or even run counter to agroecological practices. In fact, in some cases, these projects include activities which simultaneously undermine agroecology, for example, by promoting synthetic inputs and fossil fuel-based technologies. The implication here is that their budgets will not be spent entirely on activities promoting agroecology. The combined budget of these seven projects amounts to $£ 277,281,296$, or $4.74 \%$ of the budgets of the 181 projects reviewed (this percentage would decrease if the overall budget was updated as per previously mentioned) (see Figure 1). We do not want to estimate the percentage of this that would actually be spent on generating agroecological improvements but reviewing the variety of activities organised as part of each project, we can confidently say that we are looking at a minor part of these combined budgets.

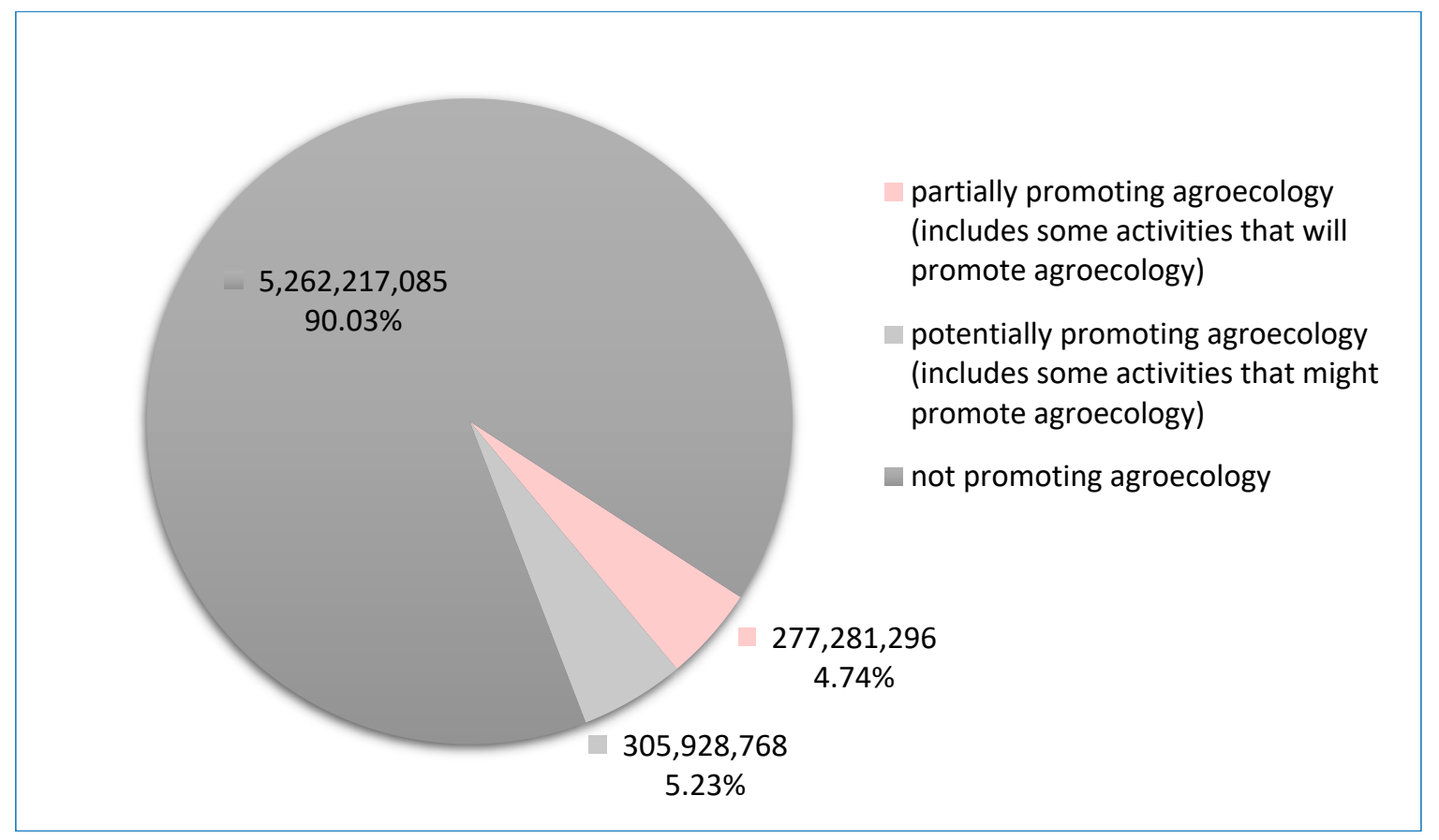

Figure 1. Aid expenditure on agriculture (spent and committed) for projects implemented or completed since 1 January 2010.

Importantly, all of the projects identified to be partially relevant to the ecological improvement of agricultural practices are only relevant to level 1 agroecology: by promoting conservation agriculture, these projects will improve soil fertility by minimizing soil disturbance (no tilling), maintaining soil cover, and rotating crops. As conservation agriculture eliminates the efforts and costs associated with ploughing, it appeals to the farming community, maybe above all, for economic and labour 
efficiency reasons. However, in contrast to organic farming, conservation agriculture allows farmers to apply synthetic fertilisers, fungicides, pesticides, and herbicides. Nonetheless, as physical, chemical, and biological soil health recovers, the use of agrichemicals may be significantly reduced over time or possibly phased out entirely.

Eight further projects have been determined to have potentially positive implications for agroecology. While these projects do not directly support agroecological practices, they promote sustainable forestry, and support research, policy development, and the procurement of technology, all of which might have supportive impacts "on the ground" for agroecological practices.

Moreover, DFID has supported two UK Aid Match projects, through which UK based charities working on international development issues have received grants matching the public donations they secured on eligible campaigns. While we were not able to obtain exact percentages, between $5 \%$ and $10 \%$ of total Aid Match funding was spent by the receiving charities on agricultural development, potentially, though by no means certainly, supporting agroecological practices. We used the generous $10 \%$ figure in our calculations. Six further projects were identified that, according to their titles, might have been supportive of agroecology; due to lack of detailed information, however, this could not be determined. We categorised a total of eight further projects, then, as potentially supportive of agroecology, due to lack of information. These sixteen projects determined to be potentially supportive have a combined budget of $£ 305,928,768$, or $5.23 \%$ of the total budget of agricultural sector funding (this percentage would decrease if the updated budget figures were used) (see Figure 1).

Again, based on reviews of activities organised, it has to be understood that even if these projects are promoting agroecology, only a fraction of their combined budgets will actually be going towards activities promoting agroecological practices.

What do these numbers mean in terms of total aid? Based on DFID figures published for the years 2010-2015, we estimate that the total DFID budget for 2010-2016 amounts to approximately $£ 60$ billion. However, figures for these years have been published in a not easily comparable form: sometimes bilateral and multilateral aid is accounted for separately, sometimes not. Adding these two figures has not led us to the same results as the totals published by DFID. In the case of incongruence, we have taken the highest figures in our calculations. For simplicity's sake, we have added GPEX and ODA figures in the same calculation, even though this might mean some overlap (double-counting of expenditure) in the year 2012. For the period of 2010-2015, we thus come to a total of (exactly) $£ 49$ billion spent on aid. In 2015, DFID total ODA was $£ 12,138$ million. Even though ODA has increased annually since 2010 (on average by $£ 1102$ million, even though from 2014 to 2015 only by $£ 438$ million), Development Tracker figures for 2016 are based on a (projected?) budget of $£ 10$ billion. We are hence basing our estimates on an estimated total aid budget of $£ 60$ billion for the period from 2010-2016.

The combined budget of the 181 identified agriculture sector projects amount to almost $£ 6$ billion $(£ 5,845,427,149)$ over that time period, or $9.75 \%$ of the total aid budget. This figure includes, however, committed budgets of projects currently being implemented, which means that part of this figure will only be spent over the next few years and therefore $9.75 \%$ is too high an estimate. Development Tracker puts the agricultural budget of 2016 at $3.37 \%$ of the total spend on aid (figures for other years are not available by sector breakdown). We are thus working on the assumption that aid expenditure on agriculture lies between $3.37 \%$ and $9.75 \%$ of total aid expenditure.

Assuming that the budget for agriculture amounts to $9.75 \%$ of the total aid budget, less than half a percent $(0.474 \%)$ of the total aid budget from 2010 onward would include activities that promote agroecology at level 1 ; that is, in the conservation agriculture form. Another half percent $(0.523 \%)$ of the total aid budget would include activities that might potentially promote agroecology at level 1.

Assuming that the budget for agriculture amounts only to $3.37 \%$ of the total aid budget, the percentages are even lower and lie at $0.16 \%$ for partially agroecology-promoting activities and $0.18 \%$ for potentially agroecology-promoting activities.

These percentages are visualised in Figure 2. 


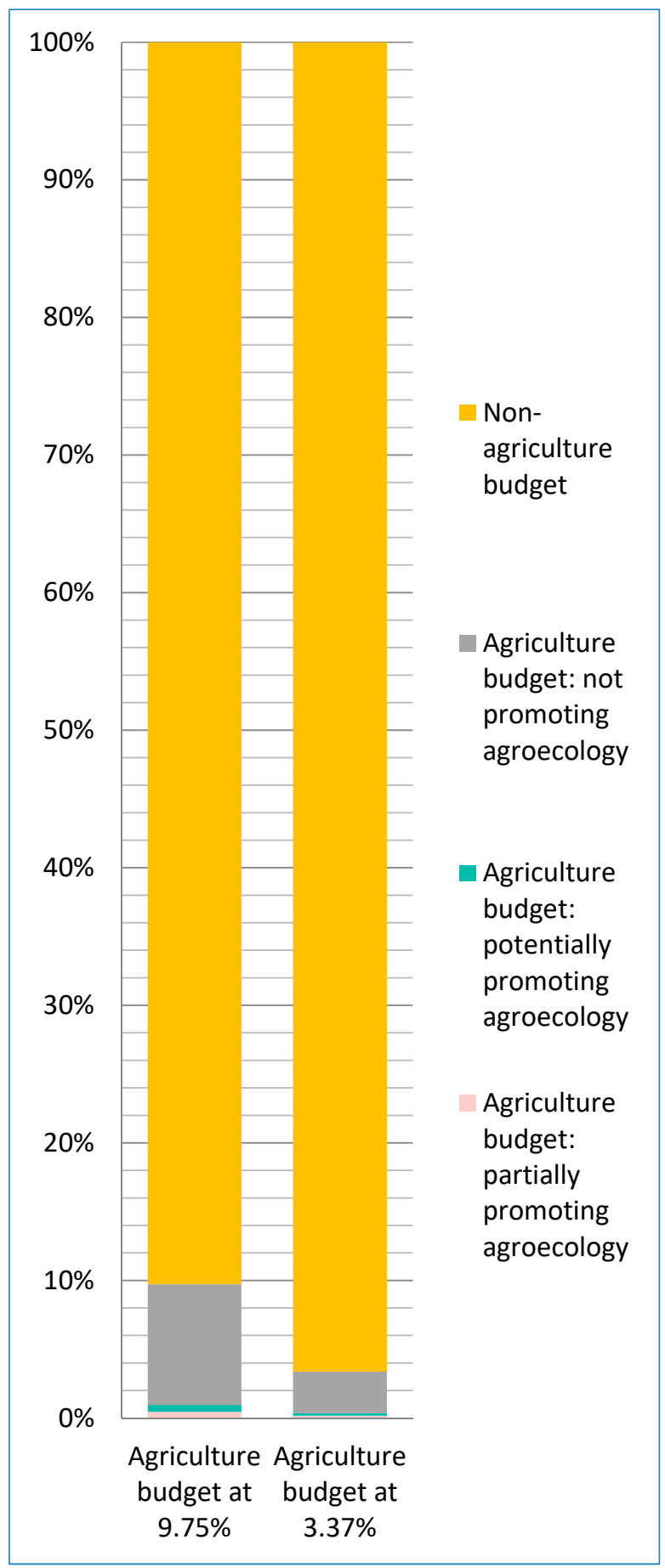

Figure 2. Aid expenditure on agriculture and agroecology-promoting projects as part of total aid budget since 1 January 2010.

Data available show that the largest share of the UK's aid budget for agriculture (over $90 \%$-see Figure 1) directly supports a model of agricultural development that is dependent on purchased external inputs (e.g., hybrid seeds, chemical fertilizers, synthetic pesticides, growth hormones, genetically modified organisms) and the linking of farmers to long value chains and global markets for the sale of farm produce. Projects that, in our analysis, do not support agroecology aim, for example, at improving access to financial services for rural populations, improving market linkages for the agricultural private sector, improving the adoption of insurance policies by smallholders, supporting 
policy development for land tenure and land markets, improving non-agricultural job prospects and the skill base of rural youths, developing large infrastructure to enable agricultural commercialisation, and improving agricultural productivity through adoption of new technologies (referring above all to synthetic fertilisers, pesticides, commercial seed, and fossil-fuel-based tilling and harvesting machinery). Notably, DFID's new approach to investing in food and agriculture-including Climate Smart Agriculture [25] — reflects the same funding and policy bias in favour of high external input and export-oriented industrial and Green Revolution agriculture, especially in Africa [26]. On the whole, UK aid thus deeply undermines the prospects for research, development, and diffusion of agroecological innovations for sustainability in Africa, Asia, and Latin America.

Evidence suggests that the patterns of aid flow we have reported here are not confined to DFID, but are likely to be global in nature. As already mentioned, with the exception of UK foreign aid, complete data on aid flows from most European countries is not available.

Since the 1970s, international summits and civil society have been urging wealthy countries to spend $0.7 \%$ of their Gross National Income (GNI) on overseas aid. This target was also seen as an important way to help meet the UN's Millennium Development Goals (and now the Sustainable Development Goals). The Group of Seven (G7)—hich consists of Canada, France, Germany, Italy, Japan, the United Kingdom, and the United States-represents the seven largest advanced economies in the world with more than $62 \%$ of the global net wealth (\$280 trillions) (the European Union (EU) is also represented at the G7 summit). In 2016, two G7 countries met the target: the UK and, for the first time, Germany. The other non-G7 countries that spent at least $0.7 \%$ of GNI included Sweden, Luxembourg, Denmark, and Norway [27]. Among the G7 countries, the United States gives by far the largest annual amount of foreign aid, although that represents only $0.18 \%$ of its national income. However, detailed and comprehensive data on aid flows from the USA are not available either.

Despite this paucity of information, it seems reasonable to assume that other European and G7 countries also provide very little funding for agroecological projects in Africa, Asia, and Latin America. There is, after all, a chronic lack of investment in agroecology within these European and G7 nations. For example, in the USA, a recent analysis of funding by the US Department of Agriculture (USDA) showed that projects with an emphasis on agroecology — of a minimum or overall level 3 in Gliessman's scheme [21]—represented only $0.6-1.5 \%$ of the entire 2014 USDA Research, Extension, and Economics (REE) budget [28].

However, further research is needed to precisely determine the extent to which overseas aid programs of G7 and European countries support agroecology (or not). In turn, this depends on governments complying with the International Aid Transparency Initiative that requires them to meet their political commitments on transparency by publishing information on money donated overseas.

\section{Conclusions}

Transformation of the dominant food and agricultural systems is urgently necessary to meet the interrelated challenges of malnutrition, poverty, ecological degradation, and other anthropogenic climate change challenges. To this end, agroecology has been identified as needing to play a central pivotal role in current agricultural development in both (so-called) developed and developing countries. Supporting agroecology as a science, as a policy framework and development methodology, as well as providing support for its civil society organisations, is required in the quest towards a more equitable and liveable world, and is vital to fulfilling the ideals envisaged in the Sustainable Development Goals [18].

In this study, we have found that despite overwhelming evidence in favour of agroecology, UK development aid barely supports the development of agroecological innovations and research. Since 1 January 2010, no funds at all have been spent on or been committed to projects with an explicit focus on development or promotion of agroecological innovations and practices.

Less than $5 \%$ of the agriculture aid budget spent and committed since 2010 (i.e., about $£ 277$ million) has supported projects that include some activities aimed at improving the efficiency of resource-use, 
resulting in fewer off-farm inputs, increased yields, and better waste reduction, and thereby can be said to partially promote agroecological development at level 1. In some cases, the same projects include activities which simultaneously undermine agroecology, for example, by promoting synthetic inputs and fossil fuel-based technologies. This amounts to less than $0.5 \%$ or $0.16 \%$ of the total aid budget since 2010, depending on which figures are used to estimate total aid.

Another $5 \%$ of the budget (i.e., about $£ 306$ million) has supported projects that might indirectly promote agroecology at level 1 -e.g., through policy development and research support-but for which a specific evaluation would be necessary in order to determine the actual impact. Again, depending on which figures are used to estimate total aid, this amounts to about $0.5 \%$ or $0.18 \%$ of the total UK aid budget since 2010.

Given the importance of the issues at stake (cf. United Nations General Assembly on the SDGs, 2015) — and the support that agroecology has found at the international level—the funds used for the promotion of agroecological research and innovations by the UK Department of International Development are, therefore, disappointingly insignificant.

By disproportionately supporting Green Revolution and industrial agriculture, UK Aid contributes very little to the transition towards social-ecological sustainability throughout the world. A substantial and radical re-prioritisation of UK overseas aid in favour of large-scale agroecological transformation is now urgently required to ensure consistency with internationally agreed SDGs-with British tax payers' money actively supporting agroecological transitions towards social-ecological sustainability in Africa, Asia, and Latin America.

Acknowledgments: This research was supported by The Agroecology Fund. This donor had no involvement in the collection, analysis and interpretation of data; in the writing of the report; and in the decision to submit this article for publication.

Author Contributions: Michel P. Pimbert and Nina Isabella Moeller conceived and designed this study; Nina Isabella Moeller analysed the data; Michel P. Pimbert provided necessary feedback on the analysis; and both authors wrote and proof-read the paper.

Conflicts of Interest: The authors declare no conflict of interest.

\section{References}

1. International Assessment of Agricultural Knowledge, Science, and Technology for Development (IAASTD). Agriculture at Crossroads. A Synthesis Report; International Assessment of Agricultural Knowledge, Science and Technology for Development; Island Press: Washington, DC, USA, 2008.

2. Food and Agriculture Organization (FAO). The State of Food Insecurity in the World; Economic and Social Development Department, Food and Agriculture Organization of the United Nations: Rome, Italy, 2009.

3. Holt-Giménez, E.; Shattuck, A.; Altieri, M.; Herren, H.; Gliessman, S.R. We Already Grow Enough Food for 10 Billion People ... and Still Can't End Hunger. J. Sustain. Agric. 2012, 36, 595-598. [CrossRef]

4. Food and Agriculture Organization (FAO); International Fund for Agriculture Development (IFAD); World Food Programme (WFP). The State of Food Insecurity in the World 2015; Meeting the 2015 International Hunger Targets: Taking Stock of Uneven Progress; FAO: Rome, Italy, 2015.

5. WHO. Obesity and Overweight. Fact Sheet (Updated June 2016). 2014. Available online: http://www.who. int/mediacentre/factsheets/fs311/en/ (accessed on 15 August 2017).

6. High Level Panel of Experts on Food Security and Nutrition (HLPE). Nutrition and Food Systems; A Report by the High Level Panel of Experts on Food Security and Nutrition; Committee on World Food Security: Rome, Italy, 2017.

7. Pothiwala, P.; Jain, S.K.; Yaturu, S. Metabolic syndrome and cancer. Metab. Syndr. Relat. Disord. 2009, 7, 279-288. [CrossRef] [PubMed]

8. Zimmet, P. Global and societal implications of the diabetes epidemic. Nature 2001, 414, 782-787. [CrossRef] [PubMed]

9. Velasguez-Manoff, M. An Epidemic of Absence: A New Way of Understanding Allergies and Autoimmune Diseases; Scribner Book Company: New York, NY, USA, 2013. 
10. Tuomilehto, J. The Emerging Global Epidemic of Type 1 Diabetes. Curr. Diabetes Rep. 2013, 13, $795-804$. [CrossRef] [PubMed]

11. Lerner, A.; Jeremias, P.; Matthias, T. The World Incidence and Prevalence of Autoimmune Diseases is Increasing. Int. J. Celiac Dis. 2015, 3, 151-155. [CrossRef]

12. Spellberg, B.; Guidos, R.; Gilbert, D. The Epidemic of Antibiotic-Resistant Infections: A Call to Action for the Medical Community from the Infectious Diseases Society of America. Clin. Infect. Dis. 2008, 46, 155-164. [CrossRef] [PubMed]

13. De Schutter, O. Report Submitted by the Special Rapporteur on the Right to Food to the 16th Session of the Human Rights Council of the United Nations General Assembly on 20 December 2010; A/HRC/16/49; United Nations General Assembly: New York, NY, USA, 2010.

14. United Nations General Assembly. Transforming Our World: The 2030 Agenda for Sustainable Development. Resolution Adopted by the General Assembly on 25 September 2015. Available online: http:/ / www.un.org/ ga/search/view_doc.asp?symbol=A/RES/70/1\&Lang=E (accessed on 27 December 2017).

15. Li Ching, L. Towards the Transformation of Our Agricultural and Food Systems; Social Watch: Montevideo, Uruguay, 2016; Available online: https:/ / www.2030spotlight.org/sites/default/files/contentpix/spotlight/ pdfs / Agenda-2030_engl_160713_WEB.pdf (accessed on 1 March 2017).

16. Standing Committee on Agricultural Research of the European Union (EU SCAR). Agricultural Knowledge and Innovation Systems in Transition: A Reflection Paper; Standing Committee on Agricultural Research (SCAR) of the European Union: Brussels, Belgium, 2012; Available online: http:/ / ec.europa.eu/research/agriculture/ scar/pdf/akis_web.pdf (accessed on 27 December 2017).

17. Farrelly, M. Agroecology contributes to the Sustainable Development Goals. Farming Matters 2016, 32, 32-34.

18. Food and Agriculture Organization (FAO). Report of the Regional Symposium on Agroecology for Sustainable Agriculture and Food Systems for Europe and Central Asia, Budapest, Hungary, 23-25 November 2016; Food and Agriculture Organization of the United Nations: Rome, Italy, 2017.

19. Levidow, L.; Pimbert, M.P.; Vanloqueren, G. Agroecological research: Conforming or transforming the dominant agro-food regime? Agroecol. Sustain. Food Syst. 2014, 38, 1127-1155. [CrossRef]

20. Altieri, M.A. Agroecology: The Science of Sustainable Agriculture, 2nd ed.; Westview Press: Boulder, CO, USA, 1995.

21. Gliessman, S.R. Agroecology: The Ecology of Sustainable Food Systems, 3rd ed.; CRC/Taylor \& Francis Group: Boca Raton, FL, USA, 2014.

22. Union of Concerned Scientists (UCS). Counting on Agroecology: Why We Should Invest More in the Transition to Sustainable Agriculture. Factsheet; Union of Concerned Scientists: Cambridge, MA, USA, 2015.

23. McVeigh, K. 'Secrecy around $£ 1$ bn aid and security fund raises 'significant concern', say MPs'. The Guardian, 7 February 2017.

24. International Aid Transparency Initiative (IATI). Datastore. Available online: http:/ / datastore.iatistandard.org (accessed on 4 December 2017).

25. Pimbert, M.P. Agroecology as an alternative vision to conventional development and climate smart agriculture. Development 2015, 58, 286-298. [CrossRef]

26. UK Government Department for International Development (DFID). Economic Development Strategy: Prosperity, Poverty and Meeting Global Challenges; DFID: London, UK, 2017.

27. Morris, C. Reality Check: How Much Does the UK Spend on Overseas Aid? BBC News. 20 April 2017. Available online: http:/ / www.bbc.co.uk/news/uk-politics-39658907 (accessed on 28 December 2017).

28. DeLonge, M.S.; Miles, A.; Carlisle, L. Investing in the transition to sustainable agriculture. Environ. Sci. Policy 2016, 55, 266-273. [CrossRef]

(C) 2018 by the authors. Licensee MDPI, Basel, Switzerland. This article is an open access article distributed under the terms and conditions of the Creative Commons Attribution (CC BY) license (http:/ / creativecommons.org/licenses/by/4.0/). 